Trask, H.K. (1993). From a Native daughter: Colonialism and sovereignty in Hawaii. Monroe, Maine: Common Courage Press.

Tuggle, C.A. \& Owen, A. (1999). A descriptive analysis of NBC's coverage of the centennial Olympics: The "Games of the Women?" Journal of sport and social issues, 23 (2), 171-182.

Wiggins, D.K. (1997). Glory bound: Black athletes in a white America. New York: Syracuse University Press.

Wong, W. (1994). Covering the invisible "model minority." Media Studies Journal, 8 (3), 49-59.

\section{The Sexuality of Gender: Gay Male SOCIAL THEORIES AND THEIR RELATIONS TO WOMEN}

\author{
ERIC OIFER \\ University of Southern California
}

\begin{abstract}
Men in various cultural locations of manhood employ heterosexual masculinity in a manner designed to maintain male privilege. This advantage relies on the exclusion of women from employing or participating in the codes of masculinity. A perspective of gender difference, that is a sense that biological women are in some important way inherently different than biological men, thus not only underlies the effort to construct male exclusivity and privilege, but it exists as an explicit category in the maintenance of men's social power. Yet, gender difference is not the only aspect of male power. The dynamic of sexuality plays an implicit role in the attempt to essentialize manhood as heterosexual, in that heterosexuality contributes to the exclusivity of men's masculine power. The hierarchical gender structure supports men's sexual and familial privileges. Among other reasons, such as their own ambiguous desires and sexual paranoia, heterosexual men exclude gay men from the category of privileged masculinity because, without sexual advantage over women, male power would be significantly weakened.
\end{abstract}

As feminist literature, from such disparate perspectives as radical and liberal feminisms, has explicated, men's sexual objectification of women is the dynamic of sex being used to maintain male power. In this context, sex can be understood as men's desires for physical pleasure and the derivation of that pleasure from objects, women, perceived as external to the subjects. Even when men do not explicitly employ that objectification, it infects their 
relations and interactions with women. Men have difficulty recognizing women's subjectivity because women are generally conceived as objects, particularly sexual objects. As a significant aspect of male power is gleaned from such heterosexually structured notions of gender, masculinity is not yet a concept comfortably open to gay men, at least in the eyes of heterosexual men. The lack of space made available to gay men within masculinity can be linked to Michael Warner's notion of "heteronormativity," which is defined by

heterosexual culture's exclusive ability to interpret itself as society. Het culture thinks of itself as the elemental form of human association, as the very model of intergender relations, as the indivisible basis of all community, and as the means of reproduction without which society wouldn't exist.

Heterosexually-defined gender difference is a dominant paradigm of the current social structure. Such an interpretive perspective functionally disables society from recognizing, let alone acknowledging, gay people as full social beings.

Gay male social theory has responded to this erasure by theoretically reconceptualizing the socially dominant codes of gender and sexuality in order to create space in the social structure for gay men. Many of those working to alter gay men's oppression through critiques of sexuality as a system of governance or through political actions like AIDS activism recognize that an important component of the marginalization of gay men is the social conception of gender. This recognition has led gay theorists both to reiterate some of the theoretical debates of feminism-such as the sameness/difference debate and the efficacy of identity politics-and to link gay social theory with feminist theory. These two fields would seem to complement each other, with related interests in overturning oppression due to sex and gender. Social theorists who address sexual politics, such as political thinker Mark Blasius and cultural critic Leo Bersani, can and have engaged in significant and important analyses of various feminist interpretations of the social and political dynamics of gender, some of which will be discussed later.

Nevertheless, while such a link between feminism and antihomophobic work might serve as a useful connection in challenging gender and sexual dynamics that structure society, it thus far has proved to be more problematic than fruitful. For instance, theorists like Gayle Rubin have been critical of what they interpret as politically problematic aspects in certain feminist literatures. She has criticized Dworkin and MacKinnon's analysis of pornography as biased towards heterosexuality. In other instances, they argue that gay theory and gay sexual practices more thoroughly challenge the sex/gender system than feminism, basically attempting to trump feminism. Thus, rather than participating in dialogue with feminism in the interest of expanding and supplementing its ideas, some social theory that focuses on sexuality often sees a conflict between feminism and its own progressive politics. Such a conflict is particularly troublesome in that these gay theoretical critiques of feminism and critical relations to women reflect some of the perspectives of male heterosexual masculinity. Those gay male social theorists who theorize things like the problem of AIDS, the politics of sex, social considerations of the body and political discourse, do so by distancing themselves from women and feminism, and tend to shift themselves, theoretically, toward dominant codes of masculinity. In particular, like heterosexual masculinist thinkers, these thinkers have employed universalizing analyses. They also have reinscribed the analytical tools developed by feminists without a complete consideration of gender and women. This article will focus on these troublesome aspects in gay male social theory, analyzing them as links between gay masculinity and the dominant ideology of male heterosexual masculinity. This focus is particularly important because, though gay male social theory is constituted by various, and often conflicting movements, perspectives and politics, certain dominant masculine codes tend to affect much of the discourse. 


\section{Gay Sex As Politics}

Gay male social theory maintains the important political goal of creating a society that does not oppress or marginalize people because of their sexuality. Towards this end, theorists in this field must analyze oppressive sexual politics as well as develop a politics that challenges dominant sexual ideology. An important thinker in this field is political theorist Mark Blasius. He explains that "how the ways individuals constitute themselves are linked with how their behavior is controlled by and controls others through a discourse of truth." He insists that lesbian and gay politics must work to expose and challenge how sexuality has been constructed through this "technology of government." Linking his analysis of sexuality to feminist literature, he explores the mechanisms by which women's oppression is rooted in the structuring of their sexuality. Dominant ideology historically has interpreted women's sexualities either within the norms of motherhood or according to a penis-centered sexuality. According to Blasius, these constructs have been analyzed by feminism through a lens of gender. For example, he argues that feminism has used Freud to expose and critique heterosexual sexuality's centering of the penis. "Feminism, as such, can encompass a politics of sexuality, but in its primary concern with gender inequality and how that inequality shapes sexuality, this politics is a politics of beterosexuality." In a sense, he asserts that a focus on gender is more applicable to heterosexuality. Thus, according to Blasius, feminism limits its own ability to challenge oppressive structures of sexuality by concentrating solely on heterosexuality.

Blasius explains that feminist theories like Catharine MacKinnon's are problematic for analyzing politics of sexuality because they recognize sex primarily as a tool, rather than an end in itself. Accordingly, feminism proscribes certain sexual acts and practices that have been associated with gay social politics, such as sadomasochism, that it sees as reinscribing the oppressive structure of gender. Consequently, Blasius feels feminism views gay sex as a device to problematize the ideological imperative of gender, rather than an act of pleasure and personal expression. For Blasius, this feminist perspective has marginalized the oppression of gays and lesbians by minimizing gay sexuality to a means rather than addressing it as an end. He challenges this maneuver by providing an analysis of how sex interacts with the system that oppresses people due to their sexuality, and not just through their sexuality. In essence, sexuality, in itself, must also be recognized as a dynamic by which people are oppressed. This is an important critique that it would seem feminism must address. Instead, Blasius argues that feminism should focus only on gender instead of broadening the application of its analysis to sexuality. He also argues that certain sexual practices touted by lesbians and gay men can provide an understanding of the hierarchical sex/gender system, as well as indicate how the system of sexual oppression can be challenged. Blasius characterizes sexual practices such as sadomasochism and butch/femme relations, as gay sex in his attempt to revalue such acts in a gay context.

While Blasius wants to value his conceptualization of gay sex as an end in itself, he also wants to employ gay sex acts as political tools. Blasius consciously essentializes certain sex acts as gay sex in order to politicize the non-heterosexual performance of such sex. Politically speaking, re-valuing sexual acts can challenge gender by altering the eminence of heterosexuality over homosexuality. Changing the view of such acts can also serve to challenge the hierarchy imposed by the structure of gender. Blasius implies that the valuing of gay sexuality is a rejection of the system by which people learn to regulate their gendered existence according to the heterosexual imperative of uniting males and females in unequal relations. Thus, he asserts that critiquing the sex/gender system from the perspective of sex rather than gender can alter the oppression of gays and lesbians, and women more generally.

While Blasius provides a progressive and insightful voice within gay sexual politics and gender politics, the aspect of Blasius' argument that focuses on using sex to challenge gender will be the point of my critique. Blasius seems to contend that the erotics 
that lesbians and gay men have developed serve as more useful tools for critiquing not just heterosexual privilege, but gender oppression. He maintains that practices such as same-sex sadomasochism challenge cultural norms and, thus, serve a politically progressive purpose.

Lesbians and gay men want to understand the heterosexist-given power relations they are enmeshed in through subjection, and they want to learn how to perceive the difference between subjection and agency by experimenting with consciously commanding and obeying, with reciprocity between top and bottom, and with the reversibility of roles.

Through such relations, lesbians and gay men obtain practical knowledge of agency and the structure of power. They can gain a clear understanding of how gendered power is organized. Also, by taking part in such constructs they recognize that such power relations can be undermined through their embodied alteration. Similarly, butch/femme relations use the façade of gender to challenge heterosexual structures of power. The butch, Blasius explains, rejects the codes of female gender while the femme sexually rejects men by embracing the butch.

Like $\mathrm{S} / \mathrm{M}$, butch/femme is the creation of agency through a power game. The refusal of gender by the butch establishes agency that was preempted by gender; the femme is an active player in getting the butch to desire her and then to take control over her erotically-and this 'active passivity' is ongoing.

Blasius asserts that both same sex sadomasochistic sex and butch/femme relations contest the sexual norms that constitute people by challenging inequitable codes of gender that are created through heterosexuality.

Blasius' discussion of same-sex sexual practices and relations establishes a potential political connection between gay men and feminist lesbians where one had not previously existed. $\mathrm{He}$ explains that Adrienne Rich's concept, the "lesbian continuum," created a political community made up of lesbians and other women, short-circuiting a similar affiliation between lesbians and gay men. Gender existed as the primary concern of lesbian feminists; they imagined that their sexuality would serve as a paradigm for women's liberation. Blasius shifts the alliance, recognizing sexuality as the location in which gay men and lesbians can collaborate to challenge gender and sexual inequality.

\begin{abstract}
...A collaborative movement has only been possible to the extent that the movement slogan 'you cannot fight heterosexism without fighting sexism at the same time' is operationalized. To the extent that it is, it creates the possibility for social relations of equality -not necessarily intimate friendships-between lesbians and gay men within what has come to be called the lesbian and gay community.
\end{abstract}

As Blasius sees the root of gender and sexual oppression as sexuality, he asserts the political link between gay men and lesbians. Such an assertion is commendable because he attempts to create allies of two groups of people who appear to have similar political interests with respect to sexuality. However, developing sexuality as an axis for this alliance tends to analytically minimize the dynamic of gender. For example, he theorizes both S/M and butch/femme as gay and lesbian sexual constructs that contest the heterosexual imperative and male dominance. That such acts can serve as valuable political tools for gay men and lesbians functions to politically link the two groups. Not only is gay sex revalued, but the essentialism of the heterosexual gender structure is also challenged. While he asserts that such acts can serve as key components to challenging both sexual and gender oppression, he establishes the progressive aspect of such sexual practices as unique to a gay context. In other words, the key to overturning both sexual and gender oppression is a politically informed gay sexuality, rather than a politics that focuses primarily on the heterosexual dynamic of women's gender oppression. 
Blasius argues for separating sex from gender in the interest of promoting sex as the primary analytical category. This support of sadomasochistic practices as progressive politics reflects those of female sex radicals like Gayle Rubin. She distances herself from radical feminists like MacKinnon in an effort to support pornography as well as a variety of other sex practices that appear hierarchical to feminists. By recognizing such activities as legitimate, Rubin wants to create a climate in which no sexual practices are prohibited because she feels that social theories of gender that problematize certain sexual activities contribute to the heterosexist stigmatization of gay sexuality. Rubin's "Thinking Sex" is motivated by what she deems feminism's inadequate analysis of sex. For instance, she sees gender analysis-the primary focus of feminismas structured by a binary vision, providing a limited notion of human subjectivity. She, instead, wants to focus on discursive models of sexuality that do not fit within a binary structure. "As soon as you get away from the presumption of heterosexuality, or simple hetero-homo opposition, differences in sexual conduct are not very intelligible in terms of binary models." She intends her analysis to be a counter to Catharine MacKinnon's, whose primary goal according to Rubin, is to establish feminism and the dynamic of gender as the basis for analyzing sexuality and sexual politics. Because Rubin devalues the significance of gender in sexual politics, she believes MacKinnon's concern with gender hierarchy hinders her analysis of sex. Similarly, Rubin criticizes Adrienne Rich's lesbian continuum for its concern with the dynamic of gender. She believes Rich evacuates sex from the category of lesbianism in order to promote gender solidarity among women.

I did not like the way in which lesbians motivated by lust, or lesbians who were invested in butch/femme roles, were treated as inferior residents of the lesbian continuum, while some women who never had sexual desire for women were granted more elevated status.

Rubin asserts that Rich's continuum limits acceptable lesbian activities so as not to disconnect itself from some women who are not comfortable with certain activities. In response to her readings of MacKinnon's and Rich's concerns with gender, Rubin argues for separating the categories of sex and gender in order to develop an analysis that focuses solely on sex.

Rubin explains that the growing field of gay male politics in the late 1970 s also motivated her interest in disconnecting sex from gender. As many gay male social theorists employed feminism as an analytical tool, feminism actually condemned much gay male behavior.

Most of the actual practice of gay male culture was objectionable to many feminists, who mercilessly condemned drag and cross-dressing, gay public sex, gay male promiscuity, gay male masculinity, gay leather, gay fist-fucking, gay cruising, and just about everything else gay men did.

In fact, alternative sexual practices, such as lesbian sadomasochism and butch/femme-which include the experience of domination and submission by the practitioners-often were interpreted as expressions of patriarchal domination. Rubin finds that gay male literature, which focuses on gay male sex in its own terms, rather than with respect to feminist categories, is much more useful to gay men, as well as lesbians who want to create space for "sexual difference." Rubin engages in this theoretical shift not as a rejection of feminism, but as an assertion that feminism is not a universal tool that should be employed to analyze all issues of gender and sexuality. Sexuality should be analyzed as its own category of oppression.

Rubin's shift from a feminist focus on gender to one based in sexuality and sexual freedom results from her desire to delimit sex and gender. For instance, Rubin rejects the standpointinfluenced feminism that asserts a priori women's authentic experiences and the appropriate activities of feminist women. She asserts that such a perspective on practices is guided by a gendered vision. Of course, Rubin is not alone in her critique. The reactions of many women, including Rubin, to such claims, are to deny their accuracy. Judith Grant explains, "This 'not me' outrage, resulting from various definitions of female 
experience has been reflected, in some circles, in an overwhelming reaction to feminist critiques of pornography and certain allegedly male-identified ways of being sexual." Sadomasochists, for instance, reject the notion that their sexual practices cannot fit within a range of authentic female sexuality. Grant develops this critique of standpoint feminism as she connects the feminist limits on appropriate female behavior with patriarchal standards of how women should behave. "Ironically, the original reason feminists extolled the recourse to female experience was to provide feminist women with a tool to use in combating stereotypical notions of women as reflected in misogynist culture." In a sense, sadomasochists such as Rubin want to reclaim that feminist sense of freedom by rejecting imposed standards. Rubin wants to achieve this by focusing on forms of sexuality that point up the distinction between gender and the body.

Despite her sympathy for sadomasochists' resistances to proscriptions of certain personal behaviors, Grant asserts that conceptually freeing gender from the body in the search for personal freedom has its limitations.

I...think it makes no sense to separate the two [gender and the body] when the ideology of gender has so invaded our understanding of the body. Without feminism, it is nearly impossible to think feminine without also thinking female body or female sex.

She emphasizes that value exists in criticizing or denouncing certain personal behaviors that contribute to systems of oppression. Feminist critique, even of other feminists, can function reasonably as social dissent if it guards "against the tendency to, in criticizing, undemocratically impose unreasonable external standards, especially upon other feminists." Accordingly, critiques of Rubin's support of sadomasochism have been made not because critics believe women could not authentically have such desires, but because such practices can have negative political consequences.
Rubin's project has been critiqued for not establishing clear lines of action or political alliances. Gay social theorist Shane Phelan explains that in her desire to link lesbians with gay men and other socially condemned "perverts," Rubin fails to consider other dynamics of oppression that might be objectionable to lesbian and other feminists. Phelan writes, "She discusses other 'deviances' from the perspective of legal harassment rather than from that of ethical questions about these practices." Specifically, Rubin's views on child pornography and incest laws are guided by her unflagging support for certain relationships and actions. Such support causes her to gloss over issues like social inequality between adults and children. In the end, Phelan explains,

The arguments of the sadomasochists are, indeed, largely liberal material; underneath the talk of community, the language of radical analysis and redemption, lies the Hobbesian acceptance of power and the Lockean focus on contract as the ground of human relations.

According to this analysis, Rubin's perspective on sexual dynamics such as sadomasochism fails to adequately consider the politics of community. Political structures that establish equality must establish limits on freedom. In her important project of legitimating a greater diversity of sexual practices, Rubin, apparently, undervalues the issue of power that often is manifested in sexuality.

Tania Modleski criticizes Rubin's failure to adequately appreciate issues of power. She argues that sex radicals such as Rubin

often minimize the issues of power and violence that one would have thought to be definitionally inherent in sadomasochistic practices, ultimately implying that whips, razors, and nipple clips are part of the panoply of devices to be used in furthering the practice of 'laudable humanistic virtues.' 
This is not to say that Modleski fails to recognize the feelings of qualitative differences between lesbian and male/female sadomasochism expressed by practitioners of $S / M$. She takes seriously the claims of choice and "mobility" expressed by lesbian sadomasochists as expressed in the SAMOIS publication Coming to Power. Modleski recognizes in the lesbian practitioners of S/M an ability both to be in their gendered roles and to recognize the irony of those roles. Instead of completely separating sex and gender, lesbian sadomasochism "enacts a complex dynamic in which existing gender arrangements are simultaneously contested and preservedpreserved partly in order to be contested." Yet, Modleski does not accept the notion that such dynamics are without problems. While lesbian sadomasochism may not replicate gender norms, it also does not adequately separate sex from gender in its analysis of desire, a move that is necessary in order to understand the effect of each. A focus on the sexual freedom inherent in various sexual acts does not free the meaning of those acts from the codes of gender. In fact, the pleasure of those acts may unwittingly come from the sense of hierarchy supplied by gender. Modleski explains that the assertions of consent and choice by $\mathrm{S} / \mathrm{M}$ proponents "mean[s] a neglect of some of the most important, indeed the defining, features of $S$ / $\mathrm{M}$-the infliction of pain and humiliation by one individual on another." Because of this requirement, the gendered aspect of S/M relations cannot be separated completely from the sexual acts that define them. While lesbian sadomasochists view the dissonance between gender and sexuality in their sex acts as progressive, Modleski asserts "there is a real danger of feminist theory's fetishizing this dissonance-and thereby preserving the structure that is supposedly being destabilized." In other words, focusing on sexuality as the key to contesting oppressive structures of gender cannot provide the kind of challenge to the sex/gender system that its proponents consider to be one of its central values. As Grant, Phelan and Modleski's critiques make clear, separating sex from gender has limited implications for sex and gender oppression primarily because such a maneuver is not completely possible.
Though Rubin and Blasius express legitimate concerns that analyses of sexual oppression must be legitimately undertaken, their critiques tend to devalue the influence of gender. Because Blasius separates sex from gender to make his primary theoretical focus sex, he undervalues criticisms of analyses that attempt to separate sex and gender. Like Rubin, he theorizes $\mathrm{S} / \mathrm{M}$ as a 'humanist' practice that enables its practitioners to understand freedom and challenge structures of oppression. Yet, Blasius' claims for separating sex and gender go beyond Rubin's. Rubin argues that such a separation enables more sexual freedom and freedom to escape sexual binarisms. Blasius maintains that in addition to such freedom a separation, in fact, enables social theory to use theories of sex to undermine the social structure of gender. The following summarizes this aspect of his project:

The technology of sexuality creates a fictive unity of the biological (sex) and the historical (gender) that "heterosexualizes" identity in sex-gender (and reproductive) complementarity. Lesbian and gay sexuality takes this unity apart and replaces it with stylization of both biological and historical elements on behalf of erotic pleasure that is also a creation of oneself as a self, as an agent in relation with others.

Blasius makes the bold assertion that sex need not be guided or limited by conceptions of gender. By imagining and practicing sex outside the borders of gender, sex can be a creative activity. Moreover, such creative acts also displace the ground of gender. In other words, by disconnecting sexuality from gender, non-heterosexual sexualities can alter the oppressive binary gender structure. No longer can sexuality be used to define socially appropriate notions of gender.

Blasius maintains that through "the eroticization of gender equality," gay men can expose and, thus, challenge the hierarchical and oppressive effects of gender on people's relationships (whether same-sex or not). In this respect, gender is the process by which cultural norms for men and women are established. Some examples of the effects of gender include the cultural illegitimacy of feminine men or masculine women. 
Moreover, constructive and limiting norms of gender contribute to social conditions that enable heterosexual men to guide women's social existences to whatever extent they do so. According Blasius' notion of eroticizing gender equality, gay male masculinity undermines the dominance of male masculinity by refusing to contribute to a structure of male power that relies on the sexual subordination of women. "For gay men, same-gender erotics involves the desire for gender equality in masculinity, while transforming what masculinity means, to the extent that it is constituted through the subordination of women." Rubin's analysis lends support to Blasius' contention about gay men's sexuality. She deems that gay male leather and S/M communities exemplify how masculinity is eroticized without employing the subordination of women. Prior to the creation of these communities the existence of the masculine homosexual was considered unthinkable according to dominant notions of sexuality and gender. Gay men were considered feminine. "In this system [of sadomasochism], a man can be overpowered, restrained, tormented, and penetrated, yet retain his masculinity, desirability, and subjectivity." In fact, the codes of masculinity have not only been claimed, but have become essential components of gay sadomasochistic erotics. According to this argument, the sexual practice of sadomasochism not only enables gay men to assert their masculinity, but also allows both partners to maintain that masculinity. Thus, gay men challenge the binary structure of gender by remaining men according to dominant masculine codes despite not desiring women as sexual objects.

This revaluation of sexual practices and the politics they promote would seem to provide a space for challenging heteronormativity and male domination. However, it works best if a distinction between sex and gender in such sexual relations are maintained. Blasius' focus on sadomasochism as the relation best able to empower gay masculinity may be true. But, such a relation does so because men's gendered empowerment remains. Moreover, in light of the arguments of Grant, Phelan, and Modleski, Blasius' conclusion about the political effects of sexual practices on gender is dubious because feminine and female, as well as masculine and male cannot be completely separated. Gendered hierarchy cannot be denied solely because members of the same sex are playing with the gendered meanings of that sex. The interconnected relationship between sex and gender is nicely summarized by Eve Kosofsky Sedgwick's study of men and sexuality, Between Men: English Literature and Male Homosocial Desire. There she explains,

It should be clear, then, from what has gone before, on the one hand that there are many and thorough asymmetries between the sexual continuums of women and men, between female and male sexuality and homosociality, and most pointedly between homosocial and heterosocial object choices for males; and on the other hand that the status of women, and the whole question of arrangements between genders, is deeply and inescapably inscribed in the structure even of relationships that seem to exclude women-even in male homosocial/ homosexual relationships.

While people of the same sex are participating in S/M or butch/ femme, the roles that they are filling are marked by dominant, heterosexual conceptions of gender. Blasius maintains that sadomasochism frees people from standard conceptions of gender and sexuality in order to challenge gay men's devalued position within the gender order. In particular, he argues that even the participant in the masochistic role can attain masculinity. Sedgwick's analysis confirms this insight. She explains that men who temporarily assume a feminized position can still "be successful in achieving a relation of mastery to other men." Thus, participants in sadomasochism can organize it so that both participants can retain masculine legitimacy. The problem with this achievement is that it is done by "the man who can proceed through that stage, while remaining in cognitive control of the symbolic system that presides over sexual exchange." In other words, while imputing masculinity into such forms of sexuality attempts to provide social legitimacy for gay men, it also revalues the oppressive gender structure that empowers men over women. 
This evaluation of sexual sadomasochistic practices is reflected in Freud's analysis of masochism. The fantasy of being beaten while retaining one's masculinity undoubtedly mirrors the Freudian masochistic structure that aids the male's ascendance to socially sanctioned masculinity. Freud's interpretation of male child's masochistic fantasies in "A Child Is Being Beaten" indicates that the boy alters his initial affection for his father into a seemingly heterosexual desire for his mother by eventually imagining her, rather than the father, as the beater. Gilles Deleuze's interpretation of this alteration maintains that it identifies the "law" with the image of the mother and functions to threaten the power of the father. This argument fails to consider Freud's explanation that the maternal figure is actually only a replacement for the repressed father figure. The motivation of this switch is the hegemonic structure of sexuality, rather than the structure of gender. The anointing of the mother as the beater is designed to elide the homosexual desire for the father which is inherent in masochism. It does not serve to challenge the law of the father. As Modleski explains, Deleuze saw the masochistic situation as humorous not in a playful or camp sense, but because of "the incongruity of placing a woman in a position of authority, of substituting her presence for that of the law." Thus, maintaining men in the positions both of the father and the beaten, as in homosexual sadomasochism, only serves to reject the repression of the homosexual aspect of the masochistic fantasy. It does nothing, in itself, to challenge the fantasy's implementation of the law of the father. At most, it indicates a sense of equality between the beater and the beaten; allowing for the beaten's entry into the symbolic structure. Gay male sadomasochism, one of the quintessential examples that Blasius uses to exemplify the dynamics of a politically progressive gay sexuality, may actually serve as a mechanism by which gay men inscribe themselves into the hegemonic gender structure that undergirds the social empowerment of male masculinity. In other words, an analysis that focuses primarily on sex rather than gender underestimates the interrelation of sex and gender. While same sex sadomasochism may not completely reinscribe the heterosexual dynamics of the masochistic fantasy, it does rely on the binary structure that defines men's gendered power and women's disempowerment.

\section{Gay Men, Masculine Imagery, and the Politics of AIDS}

In as much as Blasius' analysis inscribes gay men into a structure that characterizes dominant male power, namely sadomasochism, his analysis must be analyzed from a gendered perspective. His argument that gay men's sexual practices can challenge both sexual and gender hierarchy is constructed to establish gay male masculinity as an essential and universalizing tool for altering and constructing social existence. A primary aspect of Blasius' political ethos is what he terms erotic friendship. Within such a friendship, the two participants are considered equally independent, whole beings. "Gay erotics makes possible the creation of individual agency beyond the dependence of sex-gender complementarity and lack, which may be characterized as an invented autonomy, a new ethic." According to Blasius, this new ethical perspective exposes and undermines binary gender because it eroticizes equality rather than hierarchy. More than that, it is one from which society, in general, can view and engage in politics. Essentially, he argues that because gay sexuality is an erotic relation between people of the same biological sex, it serves as the model for social relations of equality.

While such an interpretation can provide a valuable ethic for envisioning an alternative to hierarchy and dominance, the desire for certain sexual practices to serve as universal political tools tends to reflect certain aspects of dominant masculine ideology. For instance, while discussing the equality that is generated within gay sexuality, Blasius points to gay male drag as an example of a practice that promotes equality. He argues that gay male drag challenges the heterosexually imposed structure of gender by rejecting the heterosexual need to subordinate women. "Gay male drag, for example, mocks heterosexist femininity while ironically imitating 
it to express one's desire for a man." According to Blasius, the style and expression of desire within drag empowers the practitioner as both a critic of dominant society and a provider. of an alternative vision of social existence. More specifically, the gay man in drag envisions himself as a more complete being because he embodies both femininity and masculinity. Seeing himself as a more "whole" person convinces him that he is in a position to critique the society that disempowers gay men. While such a position is felt to be empowering for gay men, employing a notion of wholeness within a social theory does not necessarily address the oppression of women. Though Blasius' analysis of gay male drag is politically potent when viewed through the lens of sexuality, its effect is less broad when analyzed through a gender analysis. In particular, while drag can be viewed as playful and somewhat freeing, it must also be understood as a fetishized activity, intended to deny the participants' culturally defined inadequacies and limitations. Men employ various mechanisms, such as drag, in response to fear of their own physical and symbolic castration. Among these tools is the fetish, which serves as a substitute for that which is missing or inadequate and helps to deny that any limitation ever existed. In fact, claiming male subjectivity as universal tends to reflect this aspect of dominant masculinity. Therefore, drag performers' use of wholeness as a basis for social critique appears to inhibit its ability to challenge the gender structure that subordinates women. Moreover, it relies on the very social structure it is critiquing, a structure that values wholeness, a subjective position culturally marked by the possession of the phallus.

This impulse to assert that gay male masculinity can challenge heterosexual manhood's hold on masculinity and legitimate social subjectivity is not unique to Blasius, but, in fact, is expressed by various gay male social theorists. Gay theorist Leo Bersani discusses the appeal of this analytical position in his "Is the Rectum a Grave?":

It has frequently been suggested...that such things as the gay-macho style, the butch-fem lesbian couple, and gay and lesbian sadomasochism, far from expressing unqualified and uncontrollable complicities with a brutal and misogynous ideal of masculinity, or with the heterosexual couple permanently locked into a power structure of male sexual and social mastery over female and social passivity, are in fact subversive parodies of the very formations and behavior they appear to ape.

While such acts have a parodic effect, the political effect of expressing masculine metaphors and symbols may face some contestation. Imputing politics into such activities and style assumes an intentionality that simply may not exist. Moreover, Bersani observes that, rather than interpreting gay machismo and sadomasochism as threats or challenges to heterosexual norms, the beterosexual can interpret them as "perversion[s] rather than subversion[s] of real maleness." As a result, even if desirable, interpreting progressive politics into gay male style and sexuality cannot be uncontentiously developed.

The contention over the gay male use of masculine codes finds expression in the gay male literature that focuses on AIDS. When this literature addresses the links between social conceptions of AIDS and notions of gay male sexuality, the issue of masculinity becomes particularly relevant. Gay social theorist Kim Michasiw contributes to this line of inquiry as he unearths the role of masculinity in both $\mathrm{D}$. A. Miller's critique of Susan Sontag's AIDS and Its Metaphors and Michael Moon's response to Sontag's analysis of Jack Smith's Flaming Creatures. He asserts,

\section{Sontag is figured by Miller and by Moon as one who denies identity, as one who travels the terrain of gay male culture armed with the prefix 'de-' and does dreadful damage. ...Sontag is understood as castratory, and worse, as constructing a 'phobic' portrait of gay masculinity which accepts tamely its cutting off from the phallus and its metaphors.}

Michasiw's analysis expresses the concern that gay thought will not be taken as seriously as other more culturally dominant forms 
of male inquiry. For instance, despite admitting that Jack Smith's work has a playful, ironic aspect, Moon clearly feels threatened by Sontag's emphasis on this lightness. To exemplify Sontag's ascribed hostility toward gay men, Moon compares her descriptions of gay camp and Jewish moral sensibilities in her "Notes on Camp." He explains that while she sees gay camp as a playful aesthetic (rather than political) solvent of social morality, Jewish social and political subjectivity is seen as based in morality. Moon's desire to see gay camp as progressive politics underlies his critical response to Sontag; he assumes that she is arguing that morality is more political and socially legitimate than aesthetics.

Miller and Moon react to their interpretations of Sontag by reappropriating the traditional masculine images she challenges. Both men employ violent and military metaphors in their responses to Sontag's analyses. Moon, for instance, completely rejects Sontag's "depoliticizing" interpretation of Jack Smith's work as joyful and innocent. He instead deems Smith's work incisive and insightful with regards to social constructions of gender and sexuality. Moon's violently imagined rejoinder asserts that Smith's work "explode[s] closets, he knew where and how to detonate it, as he was aware that setting people's closets on fire is not simply a liberatory act: inevitably, some people would get burned, including, quite possibly, the incendiaries themselves." Miller similarly responds to Sontag's desire to end AIDS activists' uses of military metaphors. He argues that Sontag fails to recognize the importance of such metaphors. He maintains that militancy conveys the image of activist "soldiers" who have fought for and achieved valuable goals, such as "increased research funding, expanded medical resources, greater access to them, human drug trial, safe sex education, and housing and legal protections for the sick." Yet, as Michasiw observes, Miller's response fails to seriously consider Sontag's legitimate concern about why AIDS activism, in its symbolism, identifies with military masculinity and finds that imagery so appealingly essential. "Similarly the embrace of masculine militancy in the face of Sontag employs the mask of different object-choice to obscure the ontological yearning for the reabsorption of gay male identity into the canons of American masculinity." Miller and Moon's works, in Michasiw's view, attempt to assert social legitimacy for gay men by claiming masculine images for them.

Such claims on the images of socially sanctioned masculinity are particularly consequential with respect to AIDS because gay male sexuality's socially assigned link with AIDS exemplifies its taboo status. The images employed by dominant society to understand and analyze AIDS tend to equate the disease with gay male masculinity. Judith Butler observes, "In some recent discourse, the male homosexual is figured time and again as one whose desire is somehow structured by death, either as the desire to die or as one whose desire is inherently punishable by death...." Dominant social discourse as guided by heterosexual masculinity denies the legitimate existence of male homosexuality. Thus, by equating male homosexual sex with social death, it can compensate for the fact that such sexuality exists. Employing a Foucaultian analysis, Butler argues that AIDS and gay activism must debunk the view that sex or limited technology to fight the disease leads to death. She feels that, instead, they must argue that a lack of proper attention to finding a cure by those in power leads to death. Such an argument is not only more politically viable, but it contributes to the delinking of AIDS and gay men.

Many AIDS and gay activists agree with Butler that this death image must be challenged and overcome. Jeffrey Weeks, for instance, argues that AIDS must be understood as a health crisis that has been exacerbated by "prejudice, discrimination, and less than benign neglect."

It is not a judgment from God, not 'nature's revenge' on any group of people, not a symbol of a culture gone wrong. HIV disease is an illness like any other, and it should be confronted with all the compassion, empathy, and resources that other major health crises demand. 
Weeks, like Butler desires to disconnect the essential link constructed between gay male sexuality and death through HIV and AIDS. In fact, Weeks argues that AIDS can create political and social links between various groups of people and provide a mechanism for appreciating diversity while striving for common goals. Additionally, in rejecting the use of metaphor when dealing with AIDS, he resembles Sontag. This similarity points out the conflicting notions of masculinity within gay male social theory. While D. A. Miller criticizes Sontag for rejecting the use of metaphor when conceptualizing AIDS, Weeks supports such a tact for contesting the dominant conceptions of the disease that link gay sex and death. Similarly, Miller criticizes Sontag's objection to gay male activist strategy such as militancy, as Weeks advocates such a position as the best way to deconstruct the essentializing of gay men as AIDS carriers.

The above alliances and conflicts are not employed in order to argue that the use of metaphor in understanding and representing gay sexuality and AIDS is always masculine, while its rejection is feminine. Rather, these metaphors often utilize masculinity and femininity. Most often, they communicate that masculinity indicates social legitimacy and femininity leads to marginalization. This being the case, gay activists face a difficult dilemma over whether to employ legitimated masculine metaphors or to establish alternative forms of activism. The feminized act of mourning, for instance, has been a mechanism used to cope with adversity. Tim Dean observes that the social process of mourning has been very public and socially legitimated in such cases as the Vietnam War. Yet, because AIDS has been a taboo issue, mourning over those lost to the disease has been largely repressed into private acts. He argues that this trend must be ended if society is to properly cope with the AIDS crisis. AIDS activists can employ the creation of the NAMES Project AIDS Memorial Quilt as an act that does not ape a dominant masculine image. In reference to the quilt, Dean maintains, "One notable instance of this effort has consisted in taking a traditionally private, domestic, feminized form of artistic practice and converting it into public spectacle." Through this tangible project of mourning, those who have died are recognized and inscribed into the social symbolic. Because those who have died are publicly named, they attain symbolic potency. Yet, those who are acting do not gain this same potency because they are acting privately through the traditionally feminine practice of quilting. Such a practice is a use of metaphor in the interest of those with AIDS that is not considered masculine.

Giving the dead, rather than survivors, symbolic potency proves problematic for AIDS activists like those in ACT UP because they only view public action by the living as the way to change social and political perceptions. Moreover, society's lack of significant action to find a cure for AIDS moves activists to think of the epidemic in terms of a war they must fight. Passive acts like mourning just do not seem to be enough. Douglas Crimp, in his article "Mourning and Militancy" explains that activists like Larry Kramer reject passivity or private expressions when dealing with AIDS.

Public mourning rituals may of course have their own political force, but they nevertheless often seem, from an activist perspective, indulgent, sentimental, defeatist.... 'Don't mourn, organize!'...is still a rallying cry, at least in its New Age variant, 'Turn your grief to anger.'

For such people, the symbolizing of AIDS victims through a typically private, feminine act is not enough because those who are living are still silenced and feminized. Crimp agrees that the constant violence and neglect that society shows those with and at great risk to get AIDS does create anger. "Because this violence also desecrates the memories of our dead, we rise in anger to vindicate them. For many of us, mourning becomes militancy." When Crimp writes "we" and "our," he refers not only to AIDS victims, but also to gay men. As society assumes gay men to be AIDS carriers, its political will to fight AIDS is lessened. This lack of political will by society is interpreted by activists as an attack on gay men and AIDS victims that must be fought with a militant will. 
The distinct move toward activism might actually be a natural product of mourning the loss of loved-ones to AIDS. In fact, it appears to develop out of anger from the loss of lives, as well as life styles. But, often AIDS activism is much more a product of melancholic anger than mourned loss. Thus, the militancy that Crimp refers to can be seen as rooted in a melancholic response to the AIDS crisis. The mourning subject relinquishes the lost object from his ego and desire so he is able to move on to and be satisfied by another object. "For people with AIDS, the HIVinfected, and those at significant risk whose sero-status is unknown to them narcissistic satisfactions in still being alive today can persuade us, will undoubtedly persuade us in our unconscious, to relinquish our attachments." Yet, the relinquishing of old attachments in order to form new attachments does not occur without a feeling of ambivalence, if not a sense of guilt at having survived. At the same time, Crimp explains that an ambivalence exists over the lifestyle that has been prevented by the AIDS epidemic. Various sexual activities and experiences that were enjoyed by gay men prior to AIDS have now been altered or completely relinquished. Thus, while these ideals are to be mourned, the mourning does not seem to be enough.

As Crimp describes it, the reaction to such losses may be more than mourning.

Perhaps we may even think of safe sex as the substitute libido-position that beckoned to us as we mourned our lost sexual ideal. But here, I think, the difference between generations of gay men makes itself felt most sharply. For men now in their twenties, our sexual ideal is mostly just that-an ideal, the cum never swallowed. Embracing safe sex is for them an act of defiance, and its promotion is perhaps the AIDS activist movement's least inhibited stance. But, for many men of the Stonewall generation, who have also been the gay population thus far hardest hit by AIDS, safe sex may seem less like defiance than resignation, less like accomplished mourning than melancholia.
The altered existence that AIDS has brought to gay men has not been universally, happily embraced. In fact, it is recognized somewhat as a punishment by some gay critics who blame the actions of other gay men for causing the changes. According to Crimp, these critics fault the gay community for causing and spreading AIDS, bringing dominant society's hatred onto themselves. Crimp recognizes this blame as melancholic. The melancholic responds to loss by imagining himself as an enlightened critic of others who have supposedly caused that loss. The gay critics that Crimp cites, such as Randy Shilts, Marshall Kirk, and Hunter Madsen, denounce the activities of AIDS activists and other gay men. These critics imagine themselves as enlightened commentators because they come from the very community they are critiquing. They react to the harm of AIDS by blaming other gay men for not becoming accepted members of society, for not acting in accordance with dominant masculine codes. Not surprisingly, these men who express melancholic sensibilities align themselves with dominant notions of heterosexual masculinity. "Their proposal centers on a media campaign whose basis is the denial of the difference. 'A good beginning would be to take a long look at Coors beer ... commercials," they suggest. According to these commercials, masculinity is a uniform concept among men that excludes any hints of femininity. Those whom these melancholic critics insist must change are the most feminine gay men, such as drag queens, fairies, etc., who do not fit the standard codes of masculinity. These melancholic expressions, which convey a form of self-criticism, serve as masculine critiques of femininities that undermine the critics' legitimate existences as gay men within general society. At the least, they reject they diversity of gay men.

Crimp attempts to reject these critics' melancholic claims by embracing the act of mourning. Such a move functions to distance his thought from gay male theory that links itself with traditional masculinity. Ironically the very notion of mourning that Crimp develops leads him to employ the masculine imagery that Michasiw critiqued in Miller and Moon's works. He explains that feelings of "militant rage" are legitimate reactions to the 
violence that gay men have experienced, and that they "must fight the unspeakable violence." Thus, while he clearly rejects the politics of those gay critics who identify with dominant heterosexual masculinity, his employment of military imagery indicates an ambivalent relationship with that masculinity. The question then remains, why must Crimp utilize a traditional masculine image to describe activities that aim to challenge the effects of dominant masculine ideology?

Employing such tools would seem to be unnecessary for Crimp, who so successfully critiques inaccurate and homophobic information provided by heterosexual society about AIDS. Rather than calling upon traditionally heterosexual images, Crimp creates truths about gay men and their sexuality on their own terms.

We were able to invent safe sex because we have always known that sex is not, in an epidemic or not, limited to penetrative sex. Our promiscuity taught us many things, not only about the pleasures of sex, but about the great multiplicity of those pleasures.

In this constructive, rather than militant manner, he is able to promote promiscuity. At the same time, he can reject those who attack it, from Shilts and Kramer to heterosexual experts who stigmatize gay sex. Perhaps, as Leo Bersani explains, ambivalence regarding the use of masculine metaphors is an essential component of gay male identity.

An authentic gay male political identity therefore implies a struggle not only against definitions of maleness and of homosexuality as they are reiterated and imposed in a heterosexist social discourse, but also against those very same definitions so seductively and so faithfully reflected by those...male bodies that we carry within us as permanently renewable sources of excitement.

Because gay men's desires for men exist alongside their rejection of a heterosexual existence, many gay male thinkers struggle to clarify those aspects of masculinity that it wants to incorporate.
More explicitly, those gay critics who reject any feminine components of gay masculinity tend to incorporate those aspects of traditional masculinity that disempower gay men.

Providing examples of how gay male sexuality has been stigmatized according to the standards of heterosexual masculinity, Bersani asserts that gay critics who embrace denigrating images give credence to such critiques. In response, he rejects the constructions of male homosexuality that connect gay masculinity to heterosexual masculinity. Tania Modleski explains:

Bersani's essay, which is an attempt to reconsider the links between sex and politics, constitutes a serious challenge to some of the orthodox thinking on this subject by gay and lesbian theorists, who in Bersani's view exhibit the same unavowed 'aversion' to sexuality as their straight counterparts and who, while insisting on the radical potential of their sexuality, tend to find this potential not in actual sexual practices but in the 'gay-life style' or in gay parody of dominant male/female roles and images.

Bersani critiques both heterosexist definitions of maleness, as well as gay thought that tends to recuperate the masculinity of gay men and gay male style. He not only focuses on gay male sex, rather than style, but also aligns gay male sex acts with femininity in order to reconfigure the cultural valuation of such categories. More to the point, he wants to make explicit the cultural essentializing of gay male sex as passive anal sex. Though malemale sexual relations take various forms, the condition that marks such sex as socially taboo is passivity. This is because sexual power indicates social power for men and "to be penetrated is to abdicate power." He explains that the cultural conceptualization of gay men can be clarified by drawing a link between the cultural representation of female prostitutes in the nineteenth century and gay men since the AIDS crisis began. Both are seen as sexually promiscuous and voracious groups, who not only spread disease, but also iconically represent infection. He describes this 
homophobic and misogynistic impression as a "seductive and intolerable image of a grown man, legs high in the air, unable to refuse the suicidal ecstasy of being a woman." Instead of denying this view of gay and female sexuality, Bersani interprets it so that it becomes an indictment of those who maintain it.

Reclaiming the value of culturally denigrated notions of femininity, Bersani rejects the cultural ideology that exiles "passive" sexuality: associated with women and gay men. Bersani's characterization of the cultural degradation of femininity serves to critique Gayle Rubin and Mark Blasius' assertion that hierarchical sex acts like sadomasochism can provide egalitarian and nurturing sensibilities. He refuses what he refers to as the "redemptive sex project" that such theorists develop; implying that hierarchical sex acts cannot be recuperated, but should be exposed for their politics and cultural assumptions. In direct contrast to Rubin, Bersani turns to Andrea Dworkin and Catharine MacKinnon's analyses of pornography to assert the cultural assumptions of gendered violence and hierarchy in sexuality. As MacKinnon has theorized, pornography eroticizes male dominance and female submission. Within this eroticization, men conceptualize women as desiring their own annihilation. Bersani summarizes this, "saying that a man lying on top of a woman assumes that what excites her is the idea of her body being invaded by a phallic master." The notion that dominant culture views both women and gay men in this same light supports his construction of sex. Thus, gay men are also understood as sexually voracious and desiring their own destruction through their sexuality.

Whereas Rubin and Blasius want to revalue gay sexuality and gay sexual practices, and feminists want to condemn gender hierarchy, Bersani actually wants to embrace the perception of gay male sexuality as passive. Tania Modleski observes, "By insisting on the pornographic nature of sexuality itself, MacKinnon and Dworkin have exposed the violence inherent in sexuality, a violence that they deplore but Bersani wants to celebrate...." He extols the disempowered (feminine) side of that violent, unequal structure, rather than the (masculine) empowered side. In other words, he espouses the efficacy of the sexual desire for powerlessness. Drawing his analysis out of a Freudian view of masochism, in which the line between the active and passive subject gets blurred, Bersani wants to give value to the experience of self-destruction. Within this masochistic experience, the destruction of the self and the relinquishing of power are not only desirable, but, according to Bersani, can serve as models for gender relations. Distrusting the model in which gender identity determines sexual identity, he wants the notion of identity to be relinquished. $\mathrm{He}$ rejects the "redemptive sex project's" desire for a sexual experience that supports the selfhood of those involved.

\begin{abstract}
As soon as persons are posited, the war begins. It is the self that swells with excitement at the idea of being on top, the self that makes of the inevitable play of thrusts and relinquishments in sex an argument for the natural authority of one sex over the other.
\end{abstract}

The self is destroyed within the masochistic experience as the subject is put in the feminine position. Thus, Bersani does not conceptualize a gay sexuality that will challenge the ideology of heterosexual sexuality. Rather, he inscribes gay male sex into the essentialized position of the feminine within the heterosexual structure. He rejects the sexual "relations of mastery and subordination...grounded in the shifting experience that every human being has of his or her body's capacity, or failure, to control and to manipulate the world beyond the self." $\mathrm{He}$ asserts instead that what gay male sexuality and desire should indicate is the desire for powerlessness in both men and women, rather than the traditional desire for male domination over women.

\section{The Shadow of Gender}

Bersani's goal of linking men and women through objectivity at the expense of their subjectivity devalues the role that gender plays in determining such categories. When men reject overt forms of power they may be attempting to disconnect from codes that mark them 
as social subjects. However, such attempts to embrace passivity do not necessarily undermine male privilege. If women, on the other hand, embrace a position of lack they only confirm the socially objectified position that marks their oppression. As Eve Sedgwick makes clear, even cases in which women claim subjectivity can be undermined by the assumed superiority of male subjectivity. Men's social power marks their perspectives as the standards for social judgement, particularly with respect to issues relating to sex and sexuality. Moreover, if male knowledge of a given issue is withheld, other views of the issue, namely women's, may be considered suspect.

The epistemological asymmetry of the laws that govern rape, for instance, privileges at the same time men and ignorance, inasmuch as it matters not at all what the raped woman perceives or wants just so long as the man raping her can claim not to have noticed (ignorance in which male sexuality receives careful education).

Thus, men who embrace passivity do not necessarily challenge the mastery and superiority of manhood.

Even focusing on specific male sex acts does not completely aid in Bersani's quest to undermine social positions of power and privilege. First, injecting politics into acts of sex imposes intention into the performers of those acts that just may not exist. Even if that political intentionality does exist, the act may not be perceived with the same meaning that it is sent. Second, and more importantly, imposing political meanings onto acts of sex limits the varieties of sex that are acceptable. Bersani essentially defines the forms of sex in which politically conscious gay men should participate. Not only does such an assertion limit acceptable forms of sexuality, but also it negatively marks people who do not engage in appropriate sex acts. Sedgwick observes:

To alienate conclusively, definitionally, from anyone on any theoretical ground the authority to describe and name their own sexual desire is a terribly consequential seizure. In this century, in which sexuality has been made expressive of the essence of both identity and knowledge, it may represent the most intimate violence possible. It is also an act replete with the most disempowering mundane institutional effects and potentials.

Thus, Bersani's theorization of passivity, which is intended as a response to those who want to recuperate same sex desire by mitigating its femininity, similarly tends to value only certain forms of sex. Such a valuation has limiting definitional effects on gay men and contributes to women's culturally objectified existences.

Bersani's analysis, which attempts to analyze the ambivalent gay identification with traditional masculinity and the structure of sexuality that it supports, fails to completely escape codes of dominant masculinity itself. Modleski explains:

It is exactly at the point where Bersani declines to factor in the 'history of male power,' however, the point where he drops the main argument of Mackinnon about how the sexuality of male supremacy fuses with the social construction of male and female, that he loses the sympathy of a feminist reader.

Modleski also maintains that Bersani's singular focus on sexuality, to the exclusion of a legitimate consideration of the category of gender, causes him to miss what is problematic in asserting sexual powerlessness for men. Male masochism does not necessarily indicate a rejection of power. Modleski asserts that "social power and sexual humiliation may coexist quite easily." Sexual activity does not equal political action. The same holds true with gender identification. As she explains, "femininity is not the same thing as...male alignment with feminism." Even if male femininity challenges dominant notions of masculinity, aligning that femininity with a powerlessness associated with women does not overturn women's disadvantaged position in the gender hierarchy. It actually relies on it. Though Bersani employs the work of Dworkin and MacKinnon, he 
underestimates Dworkin's vital point about how gender marks sex. Judith Grant clarifies Dworkin's argument, explaining that "the structure of gender shapes relationships at every level, but especially so in sexua relationships as they, in fact, depend on, imply and assume the structure, in order to 'work,' i.e. in order to be erotic." Thus, what makes male sexual passivity socially unacceptable is that it culturally signifies the participant as a disempowered woman. A refusal to consider gender politics while equating men and women according to the dynamic of sexuality fails to challenge the gendered oppression of women. In fact, it may even contribute to it.

Gay male social theorists who focus on the dynamic of sex continue to assume women's disempowered social status. The two primary, if contradictory, factors that contribute to such a postulation are theorizing that connects gay men with dominant codes of masculinity and the analytical linking of the forms of gay men's sexual castigation with women's gender oppression. Mark Blasius employs the latter strategy. By linking gay men's and women's oppressions, Blasius hopes to develop a politics that will overturn both at the same time. While his project serves an important political goal, his theory's political effect is problematized because it does not adequately separate how progressive gay male masculinity and dominant heterosexual male masculinity conceptualize men according to gender. In particular, he theorizes gay men as universal figures. He constructs gay male sexuality as the universal representative of sexual oppression, as well as the key to overcoming social hierarchies of sex and gender. Within such a figuration, women's empowerment is linked with gay male activism. In and of itself, such a link may be progressive. The difficulty is that, in this case, the link is configured hierarchically. Overturning the gender oppression of women seems to depend on the success of gay male politics. In Gay Ideas, Richard Mohr employs a similar strategy in his analysis of gay male dress. Though, his argument goes much further and is more politically and explicitly problematic for women than Blasius'. He asserts that heterosexual men traditionally employ "hypermasculine" styles to conjure degradation of women and male empowerment over them. When employed by gay men, he contends, such styles are not intended to carry the same connotations and can undermine their effect. "The gay hypermasculine is not, on the one hand, the product of trade in or over women's bodies. Nor, on the other hand, is the gay hypermasculine a flight from or an avoidance of the womanly." He observes that the use of masculine images by gay men is so overwrought that the collective image undermines the implication of domination associated with heterosexual masculinity.

Mohr primarily wants to provide an interpretation of gay masculine style that disconnects it from heterosexual masculine style. To do so, he develops the argument that heterosexual masculinity is more about the rejection of gay sexuality than the domination of women. He turns to an example that he considers the quintessential example of heterosexual sexuality, gang rape. In a rather unoriginal observation, he explains that rapists in a gang rape are motivated by desires to engage in sex with other masculine men. They, however, do not want to be identified as gay. Women, according to this logic, are incidental tools for masking these men's homosexual desires. "No hatred of women is required on the attackers' part; rather, society's hatred of women is taken by them as a permission to attack." Mohr maintains that society's hatred of women enables, rather than motivates such incidents, which are essentially expressions of hypermasculinity. He further argues that because sex between men is the true motivation of such hypermasculinity, gay sexuality exists as a truer form of hypermasculine sexuality. Yet, gay men do not employ women in the interest of denying their true desire. In this manner, their sexual activity is more honest; it does not inherently entail sexism and thus creates more potential for equality among partners. Gay male "[h]ypermasculine pairings provide a model for the background sense of equality-mutual respect-on which all other values of democracy depend." As a result, Mohr asserts gay hypermasculinity can serve as an ideal upon which practical political equality can be based.

Mohr's analysis basically excludes women as active subjects who create and participate in the politics of equality. He assumes that the equality he interprets in gay male sexuality functions to avoid the sexism usually associated with masculinity. However, his model, at best, only indicates 
equality among men. By asserting that "dread of gays is the theory" of gang rape and "the victimization of women is the practice," Mohr focuses on the erotics of such rape and neglects the gender dynamics. involved. Mohr sees women's roles in such situations as incidental. Consequently, he sees women as incidental to their own oppression. His interpretation establishes a form of trafficking in women. While Mohr's description of the homoerotics of gang rape may or may not be accurate, and is at best incomplete, his flippant use of such an example and his off-handed recognition of women's existence in the dynamic betrays his desire to create equality for gay men and women.

His focus on male erotics tends to confirm Andrea Dworkin's assertion that sexual endeavors in society exist in terms not just of gender, but also of male-defined sexuality. Furthermore, his analysis fails to respond to her claim that male dominance is the ultimate purpose of heterosexual behavior. Instead, his analysis just establishes male power as a product of homosexuality (be it repressed) rather than heterosexuality. Because his analysis minimizes the dynamic of gender, he overlooks the significance of using women's bodies as analytical tools. The physical act of gay sex between men does not involve women, but Mohr's analysis points to women as objects used to claim the superiority of gay male sexuality. His ideologically objectifying use of women does not seriously consider Dworkin's feminist assertion that "all struggle for dignity and self-determination is rooted in the struggle for actual control of one's own body, especially over physical access to one's own body." Mohr's analysis of heterosexual sex, which employs women as analytical tools in his interpretation of male masculinity and masculine codes, undermines women's subjective control of their bodies. Thus, his analysis counters his claim that gay male sex, as he conceptualizes it, does not contribute to women's oppression because women are not physically involved. However, Mohr does not recognize this limitation, but instead universalizes the value of gay sexuality. According to him, the social and sexual hierarchy implied by heterosexual male masculinity is transformed into equality and democracy when masculinity is employed by gay men. Moreover, the conditions of equality imputed to gay masculinity can precipitate the establishment of such dynamics in society in general.

In their recognition and promotion of personality and material completeness, self-sufficiency and attentive independence, in rankless friendship and intimate knowledge, and in their nonpossessive valuing wrought of robust mutual pleasure, gay male relations serve as a general model of equal respect.

Mohr not only essentializes gay male relations according to this utopian vision, but he also universalizes their value.

\section{Challenging Gender}

Searching for a universal class that will be able to alter the social structure of domination can be a valuable pursuit. Such a pursuit will not succeed without full consideration of whom that social structure dominates and in what ways. In the case of gender hierarchy, women must be recognized as important potential challengers of that structure. While analytically employing gay manhood to deconstruct the privilege and hierarchy indicated by masculinity might challenge heterosexual supremacy, it does not necessarily problematize male privilege. Judith Halberstam, in her book Female Masculinity observes,

If what we call 'dominant masculinity' appears to be a naturalized relation between maleness and power, then it makes little sense to examine men for the contours of that masculinity's social construction. Masculinity... becomes legible as masculinity where and when it leaves the white male middle-class body.

According to Halberstam, the best place to recognize and challenge masculinity as a condition of male privilege is through female masculinity. Halberstam's project challenges gender not 
by employing men to alter the codes of masculinity, but by providing an alternative version of gender in which men are not even needed for the category of masculinity to exist. By disconnecting masculinity from the male body, the privilege that it provides men can be undermined. Moreover, according to Halberstam, a democratic society based in the undermining of gender inequality, such as Mohr imagines, appears more feasible when certain positions of social subjectivity, such as masculinity, are not denied to whole classes of people, like women. Halberstam does not imply that all women must embrace masculinity in order to challenge the privilege it provides men. Rather, her analysis disrupts the essential connection between men and masculinity. Halberstam's analysis challenges the masculine/feminine binary because it disconnects the categories from specifically gendered bodies.

Susan Bordo also wants to undermine the discursive system that values what is seen as masculine over that which is considered feminine. Yet, she sees the best way to do this is to eliminate the masculine and feminine as binary categories and not to embrace one over the other. She argues that Mohr's desire to portray men as vulnerable will not "challenge the 'penetrable woman/impenetrable man' duality that 'maintains the system of gender stereotypes." On the other hand, opening the solidity of manhood to women as well will not challenge hierarchy associated with gender duality. Analyzing cultural productions, such as film and advertisements, Bordo observes that hardness, represented by muscles that "have in the past been a quintessential symbol of masculinity as a 'natural'...difference from femininity," has become acceptable for both men and women. Despite this apparent universal acceptability of masculine codes, empowered heterosexual men still remain the gauges by which gender dynamics are culturally understood or altered. She points to images from some recent gay art to make her point. For instance, Allen Ellenzweig's The Homoerotic Photograph, depicts images of non-ironic hypermasculinity that use this male heterosexual model. Unlike Tom of Finland's art used by Richard Mohr, the more recent gay images presented by Ellenzweig indicate an acceptance of the hypermasculine standard. While Tom of Finland's works intend to show gay representations challenging hypermasculinity and their heterosexual implications, the masculine images in Ellenzweig fail to provide any such contradiction. Yet, gay representations that reject the masculinity seen in Ellenzweig for an ardent femininity do not satisfy Bordo either. Her response to the conflict over whether a progressive gay manhood should embrace femininity or masculinity is to reject the duality altogether.

Bordo's view reflects that of Andrea Dworkin, who asserts that the two will always exist in a dyadic, hierarchical relation that reflects gender. Judith Grant explains, "[Dworkin] rails against femininity nearly as often as she does against masculinity, believing them both to be part of the oppressive system of gender." The debate over AIDS activism indicates the perils of embracing masculinity and a feminist analysis of masochism suggests the threat of men embracing femininity. Bordo's analysis supports that valuing one or the other establishes their hierarchical relation and reinscribes the gender structure that disempowers women. Grant's interpretation of Dworkin expands on this argument by establishing an androgynous ideal without "the familiar gender dualisms like masculinity, femininity, male and female. For Dworkin, the feminist future must move beyond dualisms with regard to sexuality, into a kind of polymorphously genderless and truly buman being." Grant establishes that such a vision is essential for an effective feminist politics that can challenge the oppressive effects of gender. She explains that gender is a structure of power that gives meaning to the "terms men and women." "The end of gender means that gender will no longer mediate the relationships between individuals and the world. Gender will also cease to mediate our relations as people." This analysis supports the notion that asserting that a particular component of gender, such as masculinity or femininity, is politically valued over another, even if it is done in the interest of overturning gender oppression, still sustains gender.

Also, such a politics risks losing support even from those who agree with its ends. An assertion that certain masculine or feminine behaviors are essential to a political challenge to the 
structure of gender may be rejected by women or feminists who feel that their own identity or experience is denied. For instance, asserting certain sexual practices as progressive and others as problematic may exclude those who are already oppressed. Grant explains, "Sexual choices can be criticized from the point of view of feminists invoking an authentic female experience from which they allege certain practices to be a deviation." This problem should not move feminism to reject sexuality, as Dworkin's analysis might imply. As Grant explains, rejecting gender in the interest of achieving equality must consider what equality and erotics should look like outside of gender. The difficulty of such a move away from gender arrangements, Grant argues, is that it entails a rejection of eroticism as it is currently constructed. Yet, refusal of the erotic in the interest of equality without gender fails to provide "a necessary discussion of the possible kinds of equality (and eroticism), and the reasons one might choose one over another." Social movements that theoretically analyze sexuality as a tool for challenging gender must analyze the effects of gender on the erotic, including same-sex sexuality.

Some gay male social theories devalue the influence of gender on sexuality when asserting that a proper configuration of sexuality, alone, can overturn the hierarchy of gender. In this light, such thinkers promote the sexual manipulation of positions within the gender hierarchy. Yet, as they continue to value one position or the other, the hierarchy remains. By connecting gay men to hypermasculinity, Mohr basically erases women as social subjects. Other thinkers express this theoretical maneuver, as well. Lee Edelman, for instance, argues that male homosexuality's use of masculine codes provides the position from which both sexual and gender hierarchy can be challenged.

Unlike gender difference...which many feminist and psychoanalytic critics construe as grounding the notion of difference itself, 'homosexual difference' produces the imperative to recognize and expose it precisely to the extent that it threatens to remain unmarked and undetected, and thereby to disturb the stability of the paradigms through which sexual difference can be interpreted and gender difference can be enforced.

For Edelman, essential notions of heterosexual sexuality determine gender difference. If reinscribed into the social structure, gay male sexuality can counter those notions and challenge dominant conceptions of what constitute men and women. Making gay men or "the homosexual" culturally visible "textualizes male identity..., subjecting it to the alienating requirement that it be 'read', and threatening, in consequence, to strip 'masculinity' of its privileged status...as natural or self-evident." Edelman's analysis maintains that alternative visions of male masculinity will undermine masculinity's overall privileged status in the gender structure. While such a project might be a valuable component in altering the dominant codes of gender, it fails to give voice to women. Edelman nevertheless hopes the deconstruction of both women's objectification in the binary gender structure and their marginalization as social subjects will be a by-product of his project. Within this project, women still are not central actors. They remain silenced as socially sanctioned space for gay men becomes opened.

Despite his theoretical marginalization of women, Edelman does draw an important link between women and gay men in his analysis of how sex produces social subjectivity. Heterosexual men interpret gay men and women as passive, and unable to become complete social subjects. According to this logic, complete social subjects are able to other sexual objects. The passive objects must serve as the antithesis to the active subjects. Heterosexual men deny women's subjectivity by defining them as the passive other. Similarly, heterosexual men interpret gay manhood as a relinquishing of empowered subjectivity in order to engage in passive sex with partners that are "interpreted as 'the same." This type of analysis draws heavily on feminist theory, such as Andrea Dworkin's. Edelman recognizes that sex, as it is linked with perceptions of gender, not only symbolizes activity or passivity, but also helps determine whether one is an object or has subjective control of one's 
existence. This observation inhibits Edelman from focusing solely on opening space for gay male participation in the codes of masculinity. He recognizes that such sexual codes contribute to the objectification and othering of both gay men and women.

In the context of this dilemma surrounding the issue of masculinity, Edelman enters the debate over what images should be employed in the rhetoric of AIDS activism. As discussed earlier, some activists believe that concepts such as war and militarism, i.e. those tied into the dominant notions of masculinity, must be employed to motivate appropriate activities. In other words, the rhetoric used by the culture that stigmatizes and oppresses gay men is also the rhetoric that some gay activists want to use. Such rhetoric has been used by Larry Kramer to attack those outside the gay community, as well as gay people whom he considers inactive in the fight against AIDS. While Edelman does not reject Kramer's attacks against "passive" gay people for "actively colluding in [their] genocide," he does resist the notion that all gay people should participate in a uniform response.

It is a question...whether we want to emulate the widespread heterosexual contempt for the image of a gay sexuality represented as passive and narcissistic in order to embrace the tanks beneath which we would lie; or whether...we want to refuse the "choice" ideologically imposed by such a binarism.

Edelman resists the notion that gay men must incorporate masculine images in order to engage in "political activism" as coherent social subjects. Instead, he wants to develop a politics of gender and sexuality that "no longer require[s] conceptualization through antithesis." To him, challenging the privilege that masculinity provides heterosexual men requires more than just opening that space for gay men.

In light of this observation, gay male social theory must include a more thorough conceptualization of gender and women's oppression in order to overturn heterosexual male domination. As Edelman's analysis exemplifies, though this need is not fully embraced, it is tenuously acknowledged. Queer theorist Michael Warner, like Edelman, observes that according to dominant social narratives, gender functions as the standard that establishes notions of difference. "In the modern West, having a sexual object of the opposite gender is taken to be the normal and paradigmatic form of an interest either in the Other or, more generally, in others." Due to this dominant paradigm, subjectivity has been linked inherently to the othering of sexual objects. In other words, men's ability to other women as sexual objects establishes men as social subjects. Similarly to Edelman, Warner argues that this heterosexual social structure must exclude homosexuality because its inclusion would undermine gender as the model of difference. Warner also recognizes that sexual difference is not just a matter of distinction, but of power. Gender and sexual oppression function as two interconnected, yet distinct social dynamics: "on the one hand the problem of women's construction as the Other, with...sources in phallocentrism; on the other hand, a sex/ gender system in which object choice is posed as an apprehension of alterity tout court." Dominant heterosexual culture perceives that gay men's object choices are narcissistic desires for the same. Such a perception hinders their acceptance as social subjects. Moreover, were they to be accepted, their inclusion could potentially challenge gender as the primary dynamic that models difference. Still, challenging that which constitutes otherness does not inherently overturn the structure of women's oppression, as women are not only other, but a devalued other. Women's disempowerment along the lines of gender must be clearly addressed, not seen as a consequence of gay liberation.

\section{Liberation Without Women}

As previously discussed, suppressing gender in the interest of sexuality actually threatens to theoretically contain women. Delimiting the two categories also fails to address the complex interaction between them. As feminist and queer theorist Biddy Martin reveals, removing sex from gender would make "sexuality, particularly homo/hetero sexual definition for men, seem strangely exempt from the enmeshments and constraints of gender (read: women)." Such an analytical maneuver would imply that 
women must identify with the sexuality associated with men in order to challenge dominant configurations of sex and gender Though linking women with male sexuality can serve to destabilize the boundaries of sexuality that serve heterosexual male interests, such as activity and passivity, "we have to be wary of the tendency to make sexuality the means of crossing, and to make gender and race into grounds so indicatively fixed that masculine positions become the emblem again of mobility." Biddy Martin implies that focusing solely on sexuality, particularly male sexuality, not only erases the gendered aspect of men's existence, but also helps to construct men as universal social figures. Men, possibly even gay men, achieve more social power and freedom while women still must rely on men for their social subjectivity.

As has been exemplified throughout, the incorporation of feminist interests into the political goals of gay men is guided by a primary focus on sexuality. The failure to recognize the significance of gender as a category, not only challenges the project of feminism, but also limits the potential effect of those gay male social theories that do this. Because gay sexuality resists the erotics of gender difference, the literature makes a significant effort to argue that gay sexuality challenges the dominant paradigm of gender difference underlying heterosexuality's structuring of society. Theorists in this area assert that the existence of gay sexuality can actually deny that gender difference should exist as a social category because such a category is not relevant in a world of fluid desires. However, as the analysis heretofore asserts, the goal of erasing gender depends upon strategies that employ a sexual freedom that is postulated, but not truly achieved. Even if that freedom is intellectually granted, gay men have not freed themselves of the dynamics of gender. The existing gender hierarchy must be considered in the social theories that are meant to indicate a path to greater freedom.

Biddy Martin observes that in those gay male social theories that attempt to deconstruct gender, "gender of the constraining sort gets coded implicitly, when not explicitly, as female while sexuality takes on the universality of man." Perhaps, this coding is that which devalues gender as a category within gay male social theory. Because women are still devalued as social objects by these gay men, the category by which they are disempowered is recognized as limiting. Yet, this devaluation, in itself, indicates that gender continues to play a role distinct from sexuality. It is not just produced by the codes of sexuality, but it can still play a significant role in determining those codes, in both heterosexuality and homosexuality. Theories of sexuality that claim to establish freedom from the hierarchical sex/gender system without weighing the effect of gender elide the dialectical relationship between sexuality and gender. The two categories do not exist in a linear relation, but interact and infect one another.

While homosexual desire may not enlist the same concern over the issues of gender sameness and difference as heterosexuality, difference still plays a role in the former. The significance of $S$ / $M$ practices in gay sexuality, as expressed by gay theorists, exemplifies the importance of some type of difference-though not biological gender difference-in gay sexual practices and fantasies. The cues for how to construct that difference might even be taken from gender difference. In his book Homos, which challenges the deconstruction of gay identity, Leo Bersani explains that sexual and social relations must be learned. The process of learning how to express desire involves "an identification with other desiring subjects." Of the available models, "the incorporation of woman's otherness may be a major source of desiring material for male homosexuals." Bersani argues that within our social structure, women serve as exemplars for how gay men express their sexuality to attract other men. He notes that gay men's use of feminine signifiers can be used politically to challenge the heterosexual need to establish an oppressive hierarchy based on difference. If both the sexual expression and object choices of men and women can be the same, the paradigm of gender difference is weakened. In other words, gay men can 
have certain political effects if they are willing to engage certain gender characteristics that they currently have, rather than deconstruct a distinctive gay existence.

In its drive to deconstruct gender and sexual difference, the gay male social theories I have been discussing minimize the significant political capacity of gender. Moreover, the theoretical refusal of gender disables much of the theories from acknowledging that men's empowered position, not just men, may appeal to gay men. Bersani, though, recognizes the two aspects of desire.

If the genealogy of desire is always also a history of the subject's identifications, and if this means that the desire to have is never entirely distinct from the desire to be, the boundaries between having and being are bound to be more blurred in same-gender desire than in heterosexual desire.

Gay men must remain aware, according to Bersani's logic, of their desire for empowered men and the social privilege that they carry with them. As has been made clear by others besides Bersani, sexual desire does not necessarily abide by political correctness. The threat of this potential sympathy with, if not desire for male misogyny is indicated by the theoretical view of male homosexuality as the key component in any challenge to the sex/gender system that structures society. Like dominant male heterosexual masculinity, such gay male theory universalizes its own position.

The centering of homosexuality within social theory serves a legitimate and important purpose. It can not only integrate gay people into the social narrative, but it can also challenge the social structures that marginalize those who are not heterosexual. As a consequence, any social theory that considers gender and sexuality, but disregards homosexuality would be inadequate. As Eve Sedgwick declares at the beginning of The Epistemology of the Closet: “...An understanding of virtually any aspect of modern Western culture must be, not merely incomplete, but damaged in its central substance to the degree that it does not incorporate a critical analysis of modern homo/heterosexual definition." By constructing gender difference as the central notion underlying social hierarchy and establishing gay sexuality as the premier challenge to the system of difference, gay male social theory moves itself to the center of progressive thought.

The problem with this theoretical shift is that this theory also tends to move gay men, to the exclusion of women, into the position of primary challengers to the dominant system. Basically, women are to rely on gay men's challenges to the sex/gender system. They tend to assert that to the extent that gay men integrate their existence into the general social dynamic, women's oppression at the hands of this system will be overturned. In essence, women are deemed an unessential part of progressive social development, even if that development is to be in their political interests. Such silencing maintains women's marginalization, despite its professed support of women's empowerment.

Gay social theory needs to attend to this theoretical consequence of silencing women through the centering of men, even if these men intend to challenge sexual and gender norms. Those doing this work can do this by making sure that they do not displace one theoretical construct with another. Rather, they need to respect and employ the insights that a gender or a feminist analysis might provide, even when that analysis seems troubling or conflicted with their intended project. This type of perspective will be best embraced through a refusal to identify their theoretical assertions with a sense of wholeness or belief that both gender and sexuality can be addressed through one perspective or another. Ultimately, in order to embrace complexity and how the voices of gay social theory and feminism can work together, clear lines of sexuality and gender both must be broken.

\section{Notes}

${ }^{1}$ Michael Warner, introduction to Fear of a Queer Planet: Queer Politics and Social Theory, ed. Michael Warner (Minneapolis and London: University of Minnesota Press, 1993), xxi. 
${ }^{2}$ Lee Edelman, Homographesis: Essays in Gay Literary and Cultural Theory (New York and London: Routledge, 1994).

${ }^{3}$ Gayle Rubin's critique, based on the assumption that Dworkin and MacKinnon are limited by a focus on heterosexuality, will be developed later in my discussion.

+ Mark Blasius, Gay and Lesbian Politics: Sexuality and the Emer. gence of a New Etbic (Philadelphia: Temple University Press, 1994), 49

${ }^{5}$ Ibid., 68.

${ }^{6}$ Ibid., 84

${ }^{7}$ Ibid., 68-85.

${ }^{8}$ Ibid., 87.

${ }^{9}$ Ibid., 85-89.

${ }^{10} \mathrm{Ibid} ., 102-3$.

"Gayle Rubin, "Interview: Sexual Traffic," interview with Judith Butler, differences: A Journal of Feminist Cultural Studies 6, nos. 2-3 (1994): 70-1.

${ }_{12}$ Ibid., 74-76.

${ }^{13}$ Ibid., 76.

${ }^{14}$ Ibid., 91.

${ }^{15}$ Judith Grant, Fundamental Feminism: Contesting the Core Concepts of Feminist Theory (London and New York: Routledge, 1993), 156-7.

${ }^{16}$ Ibid., 157.

${ }^{17}$ Ibid., 185.

${ }^{18}$ Ibid., 159.

${ }^{19}$ Shane Phelan, Identity Politics: Lesbian Feminism and the Limits of Community (Philadelphia: Temple University Press, 1989), 122-132.

${ }_{20}$ Tania Modleski, Feminism Without Women: Culture and Criticism in a "Postfeminist" Age (New York and London: Routledge, 1991), 152.

${ }^{21}$ Ibid., 155-158.

${ }_{22}^{2}$ Blasius, Gay and Lesbian Politics, 125.

${ }^{23}$ Ibid., 127-8.

${ }^{24}$ Rubin, "Interview," 96.

${ }^{25}$ Eve Kosofsky Sedgwick, Between Men: English Literature and Male Homosocial Desire (New York: Columbia University Press, 1985), 25.

${ }^{26}$ Ibid., 51.

${ }^{27}$ Gilles Deleuze, Masochism: An Interpretation of Coldness and Cruelty (New York: George Braziller, 1971), 79, 80.

${ }^{28}$ Modleski, Feminism Without Women, 155.

${ }^{29}$ Blasius, Gay and Lesbian Politics, 220-2.

${ }^{30}$ Blausius, Gay and Lesbian Politics, 128.
${ }^{11}$ Sigmund Freud, "Fetishism (1927)," in Sexuality and the Psychology of Love, ed. Philip Rieff (New York: Macmillan Publishing Company, 1993), 202.

${ }_{32}$ Leo Bersani, "Is the Rectum a Grave?" AIDS: Cultural Analysis, Cultural Activism, ed. Douglas Crimp (Cambridge: MIT Press, 1988), 206-7.

${ }^{33}$ Ibid., 207-8.

${ }^{34} \mathrm{Kim}$ Michasiw, "Camp, Masculinity, Masquerade," differences: $A$ Journal of Feminist Cultural Studies 6, no. 2-3 (1994): 167.

${ }^{35}$ Michael Moon, "Flaming Closets," October 51 (Winter 1989): n17, 36.

${ }^{36}$ Ibid., 36.

${ }^{37}$ D. A. Miller, "Sontag's Urbanity," October 49 (Spring 1989): 101.

${ }^{38}$ Michasiw, "Camp, Masculinity, Masquerade," 168.

${ }^{39}$ Judith Butler, "Sexual Inversions," in Discourses of Sexuality: From Aristotle to AIDS, ed. Domna C. Stanton (Ann Arbor: The University of Michigan Press, 1992), 345-6, 359, 361.

${ }^{t 0}$ Jeffrey Weeks, "Values in an Age of Uncertainty," Discourses of Sexuality, 389 .

${ }^{41}$ Tim Dean, "The Psychoanalysis of AIDS," October 63 (Winter 1993), 98, 99, italics added.

5.

${ }^{42}$ Douglas Crimp, "Mourning and Militancy," October 51 (Winter 1989),

${ }^{43}$ Ibid., 8-9.

${ }^{44}$ Sigmund Freud, "Mourning and Melancholia," in The Standard Edition of the Complete Psychological Works of Sigmund Freud, trans. James Strachey, vol. 14 (London: Hogarth Press, 1957), 255.

${ }^{45}$ Crimp, "Mourning and Militancy," 9.

${ }^{46}$ Ibid., 11-12.

${ }^{47}$ Ibid., 12-13.

${ }^{48}$ Ibid., 16, 18.

${ }^{49}$ Douglas Crimp, "How to Have Promiscuity in an Epidemic," in AIDS. Cultural Analysis/Cultural Activism, 253.

${ }^{50}$ Bersani, "Is the Rectum a Grave?" 209.

${ }^{51}$ Modleski, Feminism Without Women, 146.

${ }^{52}$ Bersani, "Is the Rectum a Grave?" 209.

${ }^{53}$ Ibid., 212.

${ }^{54}$ Ibid., 211-12.

${ }^{55}$ Ibid., 215.

${ }^{56}$ Catharine A. MacKinnon, Feminism Unmodified: Discourses on Life and Law (Cambridge and London: Harvard University Press, 1987), 3, 172. 
${ }^{57}$ Bersani, "Is the Rectum a Grave?" 214.

${ }^{58}$ Modleski, Feminism Without Women, 147-8.

${ }^{59}$ Bersani, "Is the Rectum a Grave?" 218.

${ }^{60}$ Ibid., 216

${ }^{61}$ Eve Kosofsky Sedgwick, Epistemology of the Closet (Berkeley: University of California Press, 1990), 4-5.

${ }^{62}$ Ibid., 26.

${ }^{63}$ Modleski, Feminism Without Women, 148.

${ }^{6+}$ Ibid., 149-150.

${ }^{65}$ Judith Grant, "Dworkin and Sade: The Erotic Victim," Strategies 8 (Winter 1995/1996), 103

${ }^{66}$ Richard D. Mohr, Gay Ideas: Outing and Other Controversies (Boston: Beacon Press, 1992), 164-167.

${ }^{67}$ Ibid., $184-5$.

${ }^{68}$ Ibid., 195-6.

${ }^{69}$ Ibid., 185.

${ }^{70}$ Andrea Dworkin, Pornography:Men Possessing Women (New York:Plume, 1979), 34-5.

${ }^{71}$ Ibid., 203.

${ }^{72}$ Mohr, Gay Ideas, 201.

${ }^{73}$ Judith Halberstam, Female Masculinity (Durham and London: Duke University Press, 1998), 2, 9.

${ }^{74}$ Susan Bordo, "Reading the Male Body," Michigan Quarterly Review 32, no. 4 (Fall 1993), 720.

${ }^{75}$ Ibid., $723-4$.

${ }^{76}$ Ibid., 726.

"Grant, "Dworkin and Sade," 100.

${ }^{78}$ Ibid., 102.

${ }^{79}$ Grant, Fundamental Feminism, 183.

${ }^{80}$ Ibid., 157-159.

${ }^{81}$ Grant, "Dworkin and Sade," 105-106.

${ }^{82}$ Lee Edelman, Homographesis: Essays in Gay Literary and Cultural Theory (New York and London: Routledge, 1994), 11.

${ }^{83}$ Ibid., 12.

${ }^{84}$ Ibid., $104-5$.

${ }^{85}$ Larry Kramer, "Oh, My People," in Reports from the Holocaust: The Making of an AIDS Activist (New York: St. Martin's Press, 1989), 163.

${ }^{86}$ Edelman, Homographesis, 109.

${ }^{87}$ Ibid., 116.
88 Michael Warner, "Homo-Narcissism; or, Heterosexuality," in Engendering Men: The Question of Male Feminist Criticism," ed. Joseph A. Boone and Michael Cadden (New York and London: Routledge, 1990), 190.

${ }^{89}$ Ibid., 203.

${ }^{90}$ Biddy Martin, "Sexualities Without Genders and Other Queer Utopias," diacritics 24, no. 2-3 (Summer-Fall 1994), 107.

${ }^{91}$ Ibid., 110.

${ }^{92}$ Biddy Martin, "Extraordinary Homosexuals and the Fear of Being Ordinary," differences 6, no. 2-3 (1994), 102.

${ }_{93}^{9}$ Leo Bersani, Homos (Cambridge and London: Harvard University Press, 1995), 60-1.

${ }^{94}$ Ibid., 63-4.

${ }^{95}$ Sedgwick, 1. 